\section{Rare intrathoracic complications in acute pancreatitis}

\author{
David J Shewring, Harold G Naerger, \\ Howard W Steer
}

\begin{abstract}
Ascites and pleural effusions may complicate pancreatitis but pericarditis with pericardial effusion and tamponade is rare and necrosis of mediastinal fat has not been described before. All these complications occurred in the case reported here.
\end{abstract}

Acute pancreatitis commonly causes effusions of the lesser omental sac and pleural spaces. Clinically important pericardial effusions are rare, ${ }^{1-4}$ but may result in tamponade. Pericarditis diagnosed postmortem and associated with acute pancreatitis has been reported. Our case illustrates that cardiac tamponade should be considered when unexplained deterioration occurs in a patient with pancreatitis.

\section{Case report}

A 56 year old man was admitted for examination under anaesthesia and diathermy of rectal polyps, a procedure he had undergone many times since a total colectomy and ileorectal

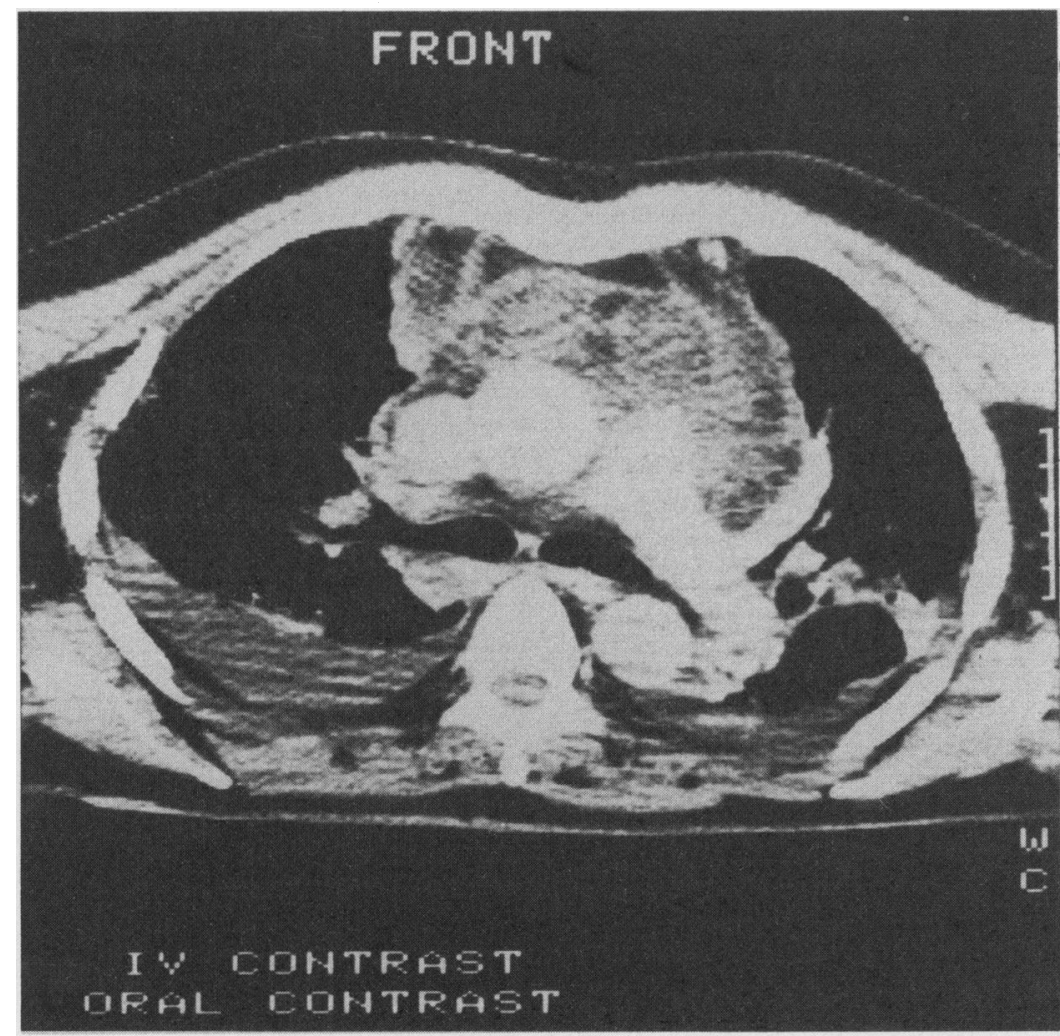

Thoracic computed tomogram showing an anterior mediastinal collection in addition to bilateral pleural effusions. anastomosis for polyposis coli 13 years earlier. Six hours after operation he developed epigastric pain and became hypotensive with a systolic blood pressure of $75 \mathrm{~mm} \mathrm{Hg}$. Chest and abdominal radiographs were normal. A diagnosis of acute pancreatitis was made and he was treated conservatively with intravenous fluids and analgesia. His condition improved, but two weeks later he developed further pain and jaundice (table). Abdominal computed tomography showed a pseudocyst and a dilated common bile duct due to compression by an inflamed pancreatic head. A laparotomy was performed to drain the pseudocyst and create a cholecystostomy and parenteral feeding was started the day after.

Thirty eight days after the onset of the illness the patient suddenly deteriorated, complaining of chest pain and breathlessness. He became hypotensive with a systolic blood pressure of $70 \mathrm{~mm} \mathrm{Hg}$ and tachycardia of $150 / \mathrm{min}$. He had pulsus paradoxus and a central venous pressure of $20 \mathrm{~cm} \mathrm{H}_{2} \mathrm{O}$. A chest radiograph showed a widened superior mediastinum, an enlarged cardiac shadow, and a left sided pleural effusion. An electrocardiograph showed changes consistent with pericarditis, and an echocardiograph showed a pericardial collection. Thoracic computed tomography showed a fluid collection in the anterior mediastinum (figure).

Aspiration of the pericardium was unsuccessful and a thorocotomy was performed. Thick straw coloured fluid $(400 \mathrm{ml})$ was drained from the pericardium, resulting in immediate haemodynamic improvement. The amylase content of the fluid was 2240 IU/1. The anterior mediastinum was explored and $200 \mathrm{ml}$ of thick yellow fluid obtained. Subsequent analysis showed that this was necrotic fat. A contrast study via the cholecystostomy tube 120 days after admission showed normal calibre bile ducts and free flow into the duodenum.

The patient was discharged after four months as an inpatient, two of which were spent in intensive care.

\section{Discussion}

The mechanism of pericardial effusion in acute pancreatitis is unknown but various theories have been proposed. These include chemical pericarditis due to circulating enzymes, ${ }^{\dot{2}}$ fistulous connections between pericardial and abdominal cavities, ${ }^{3}$ and lymphatic transport of amylase. ${ }^{6}$ In our case the amylase content of

Serum amylase, alkaline phosphatase, and bilirubin concentration over 200 days of observation

\begin{tabular}{lrrrrrr}
\hline Day & 1 & 13 & 38 & 120 & 140 & 200 \\
\hline $\begin{array}{c}\text { Amylase (IU/1) } \\
\text { (NR 25-85) }\end{array}$ & 3100 & 2900 & 4240 & 171 & 130 & 100 \\
$\begin{array}{c}\text { Alkaline phosphatase } \\
\text { (IU/1) (NR 30-135) }\end{array}$ & 172 & 1908 & 1532 & 1647 & 1389 & 500 \\
$\begin{array}{c}\text { Bilirubin (mmol/1) } \\
\text { (NR 2-17) }\end{array}$ & 8 & 72 & 14 & 48 & 38 & 19 \\
\hline
\end{tabular}

NR-normal range. 
the pericardial fluid lends support to a local mechanism.

Fat necrosis has been well documented in subcutaneous tissues in pancreatitis ${ }^{7}$ but it has not previously been described in the mediastinum. Mediastinal extension of a pancreatic pseudocyst has been described, but in our patient neither contrast studies nor computed tomography showed a fistulous connection.

Our case also shows the importance of a multidisciplinary approach, without which our patient would probably not have survived.
1 Auger C. Acinous cell carcinoma of the pancreas with extensive fat necrosis. Arch Pathol 1947;43:400-5.

2 Mitchell CE. Relapsing Pancreatitis with recurrent pericardial and pleural effusion. Ann Intern Med 1964;60:1047.

3 Lipson JD, Stephenson HE. Pancreatitis complicated by pericardial effusion and cardiac tamponade. Arch Surg 1971;103:414.

4 Witherington R, Collins P. Cardiac tamponade in acute pancreatitis. Thorax 1980;35:959-60.

5 Jones B, Haponick EF, Katz R. Fibrinous pericarditis: an uncommon complication of acute pancreatitis. South Med $J$ 1987;80:377-8.

6 Perry TT. Role of lymphatic vessels in transmission of lipase in disseminated pancreatic necrosis. Arch Pathol 1947; 43:456-65.

7 Wilson HA, Askari AD, Neiderhiser DH, et al. Pancreatitis with arthopathy and subcutaneous fat necrosis. Arthr Rheum 1983;26:121-6.

\section{LETTER TO THE EDITOR}

\section{Intercostal arteriovenous fistula due to pleural biopsy}

We read with interest the report by $\mathrm{Dr} \mathrm{J}-\mathrm{H}$ Lai and others (December 1990; 45:976-8) of an intercostal arteriovenous fistula complicating a routine pleural biopsy.

We all agree that this blind procedure may lead to complications that are very occasionally life threatening. To avoid traumatising the intercostal blood vessels the biopsy needle should be introduced just above the rib as recommended by the authors. In addition, the biopsy groove of the needle should be kept facing either medially or laterally along the intercostal space. The actual direction of the biopsy groove was not stated in this report, though it may have been an important factor complicating the fourth attempt at pleural biopsy.

SM TARIO K McCONNOCHIE
Chest Unit,
Llandough Hospital, Cardiff CF6 1 XX

AUTHORS' REPLY We are grateful for the reminder about the possibility of placing the biopsy needle in the wrong direction when the pleura is punctured. We agree that this is important. The biopsy was performed with the groove in four directions-medial, medioinferior, inferolateral, and lateral in that order. We had not met the complication of arteriovenous fistula previously. To minimise the risk of injury to intercostal vessels and nerves when the procedure is carried out in this way samples .of pleura should be obtained only from the lateral, medial, and inferior margins of the site where the needle punctures the pleura.

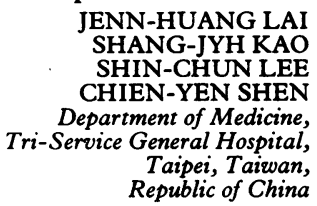

Kinasewitz GT, Fishman AP. Pleural dynamics and effusion. In: Fishman AP, ed. Pulmonary diseases and effusion. In: Fishman AP, ed.Pulmonary diseases and disorders. 